\title{
Towards an ecosystem approach for understanding public values concerning marine biodiversity loss
}

\author{
Adriana Ressurreição ${ }^{1, *}$, Tomasz Zarzycki ${ }^{2}$, Michel Kaiser ${ }^{3}$, \\ Gareth Edwards-Jones ${ }^{4, \mp}$, Tomaz Ponce Dentinho ${ }^{5}$, Ricardo S. Santos ${ }^{1}$, James Gibbons ${ }^{4}$ \\ ${ }^{1}$ Centre of IMAR of the University of the Azores, Department of Oceanography and Fisheries/UAz \& LARSyS \\ Associated Laboratory, Rua Prof. Dr. Frederico Machado 4, 9901-862 Horta, Azores, Portugal \\ ${ }^{2}$ Institute of Oceanography, University of Gdansk, Al. Marszalka Pilsudskiego 46, \\ Gdynia Pomorskie 81-378, Poland \\ ${ }^{3}$ School of Ocean Science, Bangor University, Menai Bridge, Anglesey LL59 5AB, UK \\ ${ }^{4}$ School of the Environment, Natural Resources \& Geography, Bangor University, Gwynedd LL57 2UW, UK \\ ${ }^{5}$ Department of Agrarian Sciences, University of Azores, Terra Chã 9701-851, Angra do Heroismo, Portugal
}

\begin{abstract}
Recent European legislation requires the adoption of an ecosystem-based approach for managing marine systems in which societal values and good science contribute to attainment of 'good environmental status' for Europe's seas by 2020. At present, there is a lack of studies that consider public values for marine biodiversity changes taking into account the cultural diversity within Europe. We used a contingent valuation survey to explore respondents' marginal willingness to pay (WTP) and motivations to prevent 3 levels of species loss (10, 25 and $50 \%$ ) as compared to current levels for fish and all marine species. The survey was undertaken in 2 sites: the Azores islands (NE Atlantic) and the Gulf of Gdansk (Baltic Sea). Results, based on 747 interviews, showed that motivations underlying WTP for marine species conservation encompassed primarily bequest values and direct use values. Respondents from different locations differed in their attitudes and values towards marine biodiversity conservation. Scope tests revealed significant differences in WTP for different levels of species loss; however the magnitudes of the scope sensitivity were constrained by a lack of awareness about the consequences of biodiversity changes and the welfare tradeoffs involved. This result highlights the need for the scientific community to better communicate knowledge about the link between biodiversity changes and human wellbeing and to embrace a fuller dialogue between policymakers and the public. A successful ecosystem based approach must accommodate the diversity of preferences and hence may need to be adapted to reflect regional diversity within Europe.
\end{abstract}

KEY WORDS: Marine biodiversity changes - Marginal values - Cultural diversity - Scope sensitivity $\cdot$ Contingent valuation $\cdot$ Willingness to pay $\cdot$ Species loss $\cdot$ Payment card

\section{INTRODUCTION}

Human-dominated seascapes have a long history of overfishing and habitat degradation in Europe and beyond. While the drivers and magnitude of this loss have been widely characterised (Myers \& Worm 2003, Pandolfi et al. 2005, Morato et al. 2006,
Coll et al. 2010), the impact of this loss on human wellbeing remains scientifically unclear and thus poorly understood by the public and policy makers (Carpenter et al. 2009, Mooney \& Mace 2009). A recent study on attitudes of Europeans towards the issue of biodiversity (Eurobarometer 2010) revealed that only a minority of EU citizens felt well informed 
about biodiversity loss and most saw no immediate personal impact. In addition, citizens' perceptions regarding the seriousness of biodiversity loss in each member state varied widely across Europe showing the importance of social elements in achieving effective adaptive management.

To sustain a future in which human societies and healthy oceans live together, people's values, perceptions and uses of marine biodiversity must be recognized as intrinsic components of management plans (Barbier et al. 2008). The ecosystem-based management underlying this premise has recently been proposed within the European Union as a decisionmaking strategy to optimise the social and ecological functions of Europe's seas (Mee et al. 2008). While, in theory, emphasis is given to social and biophysical components of marine systems, in practice the contribution of socio-economic studies for the European marine policy has lagged behind in terms of policy formulation, monitoring and evaluation (Symes \& Hoefnagel 2010). To overcome this gap and ensure more efficient and equitable conservation policies, there were increasing calls to estimate the value of environmental goods and services (e.g. Carpenter et al. 2006, 2009, Sutherland et al. 2009, TEEB 2010).

Economic valuation can be defined as a methodo$\operatorname{logy}$ to assign quantitative values to natural resources, whether or not a market exists for the good (Subade 2007). By converting the multiple benefits of biodiversity to a single metric, economic valuation translates the complexity of ecosystems into terms that decision makers and the general public can easily understand (Carpenter et al. 2006). However, economic values are policy-irrelevant unless coupled with an understanding of how people are arriving at their values (Martín-López et al. 2008, Spash et al. 2009). From a strict utilitarian perspective people may be interested in protecting biodiversity based on the use values that are consumed directly (e.g. fisheries, recreation) or used indirectly throughout ecosystem services (e.g. erosion control, climate regulation, water purification). On the other hand, people's values may be related to the non-use components of biodiversity, namely existence values (the value of knowing that some species or habitats exist) and bequest values (the value of conserving species and habitats for future generations). Identifying the motivations underlying people's values is critical for understanding how individuals make choices involving environmental goods and to identify social concerns about environmental changes.

Another key challenge for conservation science is to understand the role of socio-geographic and cul- tural contexts in shaping people's values (Ressurreição et al. 2012). Europe has a complex cultural history, which is reflected in each seascape and its associated biodiversity (Pullin et al. 2009). In addition, marine biodiversity is not distributed evenly over marine regions, and the variability can be large between member states. Social, ecological and cultural diversity across Europe influences how individuals interact with the marine environment, how they perceive it and, ultimately, how they value it (Ressurreição et al. 2012). Regional and national assessments provide valuable information for the wise use of marine resources and allow for a better adjustment to the specific cultural contexts where conservation management tends to be made. Nonetheless, the transboundary nature of the marine environment requires further understanding on how societal values and perceptions vary across locations and temporal scales. To achieve this capacity, concerted international efforts are needed. However, because of the difficulties of carrying out coordinated assessments in multiple places most previous valuation studies have tended to be geographically specific (White et al. 1997, 2001, Langford et al. 1998, Bosetti \& Pearce 2003).

There is much research on human impacts on ecosystems but we lack basic information on how changes in biodiversity influence human wellbeing and how society perceives and values these changes (Cornell 2010). With the present work we seek to bridge this gap by estimating the public's willingness to pay (WTP) to prevent loss of marine species using a contingent valuation method (CVM). The transboundary nature of the marine environment requires regionally coordinated policies and actions. The present study aims to compare the public's marginal values to avoid the loss of marine species in 2 casestudy sites covering 2 contrasting marine regions in Europe: the Azores islands (Portugal, North East Atlantic) and the Gulf of Gdansk region (Poland, Baltic Sea).

We do not attempt to comprehensively review the validity of CVM, since this has been done elsewhere (Carson \& Mitchell 1995, Venkatachalam 2004). Rather, we were interested in understanding how individuals value different levels of marine species loss from the status quo in different locations. Specifically, our study aimed to (1) estimate marginal values associated with increased levels of species loss $(10,25$ and $50 \%$ reduction of species richness) in fish and in all marine species at the regional scale, (2) evaluate whether the WTP estimates are an increase function of the scope of species loss and (3) examine 
the motivations underlying stated WTP values. Differences in WTP were also tested between casestudy sites and between residents and visitors. Because the future of marine biodiversity depends so much on human behaviour, we feel that the discussion of socio-economic aspects of biodiversity changes complements ecological data and provides a practical aid for ecosystem services research to become more immediately policy relevant.

\section{METHODOLOGY}

\section{Study areas}

Our study involves 2 case-study sites with contrasting social, cultural and ecological features: the Azores islands (Portugal, North East Atlantic) and the Gulf of Gdansk (Poland, Baltic sea). Sites were selected among partner countries involved in the EU Network of Excellence: Marine Biodiversity and Ecosystem Function (MarBEF; www.marbef.org).

The Azores are a remote archipelago in the central Northeast Atlantic $\left(36-40^{\circ} \mathrm{N}, 24-32^{\circ} \mathrm{W}\right)$. They comprise 9 inhabited islands and several islets scattered in 3 main groups along $600 \mathrm{~km}$ of the Mid-Atlantic Ridge. The coastline is $\sim 790 \mathrm{~km}$ in length (Menezes et al. 2006) defining an exclusive economic zone of 1 million $\mathrm{km}^{2}$ with an average depth of $3000 \mathrm{~m}$. Endemic diversity is low but pelagic and deep-sea diversity is high. Due to the isolated position in the middle of the Atlantic and low population density, the overall quality of the marine environment is good but the effects of over-fishing in some species and vulnerable habitats are raising concern (OSPAR 2010). The small-scale economy of the region is based on agriculture, fisheries and tourism. Commercial fisheries and recreational marine activities (e.g. whale watching, big game fishing, SCUBA diving, shark diving) are of considerable importance to the economy and cultural identity of the Azores. Owing to the impracticality of undertaking a questionnaire in all islands (due to time and budget constraints), 2 islands of the central group - Pico and Faial - were chosen as the location for this study. Divided by a strait $8.3 \mathrm{~km}$ long, these islands are geographically, socially and culturally connected and have a daily interchange of residents and visitors.

The Gulf of Gdansk, in the south of the Baltic Sea, is a system of shallow brackish waters with an average depth of $59 \mathrm{~m}$. The total surface area of the Gulf of Gdansk comprises $4940 \mathrm{~km}^{2}$ with a volume of $\sim 291 \mathrm{~km}^{3}$ (Majewski 1994, Kruk-Dowgiałło \& Sza- niawska 2008). The southern Baltic is considered a low-diversity system (HELCOM 2009). Consequently, marine and coastal biodiversity in the Gulf of Gdansk is barely noticed by the public (Zarzycki 2011). High population densities, intensive farming and highly developed industry around most of the Baltic Sea have lead to a significant increase of nutrients and pollution over the past decades (Glasby \& Szefer 1998). Fisheries are a small part of regional GDP and the main economic sectors include shipbuilding, oil refining, food processing and tourism.

\section{CVM}

Economic techniques such as CVM are designed to disclose the value of environmental goods and services that are not directly observable by market transactions. In such circumstances, simulated markets are created in which citizens are asked for their maximum WTP to protect species, ecosystem services or habitats. In the context of species valuation, the CVM is one of the most accepted approaches among environmental economists (Loomis \& White 1996, Martín-López et al. 2008, Richardson \& Loomis 2009). Indeed, a recent meta-analysis of threatened and endangered species valuation studies (Richardson \& Loomis 2009) revealed that only one study (Layton et al. 2001) did not use the CVM. Despite being widely used, the applicability of this method is debated given the difficulties in quantifying the benefits of conservation in monetary terms (particularly less tangible benefits, such as existence value of biodiversity) and the potential discrepancy between stated and real WTP. In order to generate estimates that are meaningful in an economic perspective, individuals are expected to act as selfinterested and perfectly rational beings that seek to maximise a quasi-concave utility function and to express values for different states of the world according to complete, stable and convex preferences (Chee 2004, Fischer \& Hanley 2007). The assumption that individuals behave as predicted by economic theory is strong for well-defined markets and even more challenging for environmental goods. Common biases in CVM include hypothetical bias (divergence between real and stated WTP), information bias (negative or positive effect of the information conveyed in the survey in stated WTP), and scope insensitivity (invariant WTP regardless the scope of the good), and care has to be taken during the study design and when interpreting results of contingent valuation (CV) exercises. 


\section{Survey instrument, study design and data collection}

The initial stage of this research comprised close cooperation between the economists and natural scientists involved in MarBEF. Inputs from these experts helped to define the valuation scenarios, target population, study design and sampling strategy. In this context economic valuation was not used for the appraisal of a specific project but to test and indentify societal preferences for marine biodiversity using 2 contrasting case-study sites within Europe in order to improve the design of conservation policies.

Overall the survey instrument included 25 questions intended to examine respondents' general behaviour, knowledge and attitudes towards the conservation of marine biodiversity, the economic valuation exercise and socio-demographic data (see the supplement at www.int-res.com/articles/suppl/m467p015_supp.pdf). Standard protocols and recommendations for mitigating bias in CV surveys (e.g. Mitchell \& Carson 1989, Arrow et al. 1993: NOAA panel guidelines) were followed and are summarised in Ressurreição et al. (2012) along with a full description of the questionnaire, study design and sampling strategy. Key differences regarding the valuation scenarios and scope tests used in this survey are described in the following sections.

The CV survey was undertaken in the summer of 2008 and of 747 questionnaires were completed between visitors $(\mathrm{n}=252$; Azores $\mathrm{n}=127$, Gdansk $\mathrm{n}=125)$ and residents $(\mathrm{n}=495$; Azores $\mathrm{n}=119$, Gdansk $\mathrm{n}=376$ ). The face-to-face interviews were carried out by trained interviewers, and respondents were randomly selected in public places in order to cover a representative range of residents and visitors. We aimed to target $\sim 250$ respondents at each location. Extra budget and human resources allowed us to double this number in the Polish case-study site (Azores $\mathrm{n}=246$, Gulf of Gdansk region $\mathrm{n}=501$ ). A payment card design was used to elicit the WTP of the respondents. As the monetary currency varied between case studies, the payment cards were expressed in local currencies (Azores: Euro [€]; Poland: Zlotys [Zł]), and the ranges of the bids presented in the payment cards were defined by a series of open-ended pre-tests (Azores $\mathrm{n}=67$, Gdansk $\mathrm{n}=35$ ). Pre-tests also defined the payment vehicle used in the survey as a one-off payment to a conservation trust fund.

\section{Valuation scenarios for marine species loss}

The valuation scenarios aimed to identify biodiversity changes that were comprehensive in ecological terms as well as relevant and understandable to participants. A recent study underlined that citizens understand biodiversity loss mainly as a speciesfocused concept (Eurobarometer 2010). Further, loss of biological diversity because of extinction, at local or regional scale, is one of the most obvious and tangible metrics of biodiversity change (Cadotte et al. 2008) providing a measurement that can be easily compared between case-study sites. Hence, marine biodiversity changes were considered in terms of species richness within an area and respondents were asked to express WTP values to prevent different levels of declines in the number of species of fish and in all marine species from the current level. The rationale for these choices was to go beyond the single and charismatic species approaches and the recognition that the value of ecosystem services provided by marine biodiversity is conditional on a well functioning ecosystem.

Follow-up questions explored underlying motivations for positive and negative WTP questions allowing the distinction between genuine zero bidders (those respondents who cannot afford to pay or whose welfare is unaffected by the good being valued) and protest responses (respondents who state zero as a protest stand). Protests if identified are usually censored from data analysis (Mitchell \& Carson 1989). Respondents were also encouraged to justify the scope sensitive and non-scope sensitive responses and to take income constraints into account.

\section{Scale of change and scope tests}

To test for scope sensitivity we used a within sample design, and respondents were asked to express values to avoid 3 levels of species loss $(10,25$ and $50 \%$ ) for fish and then all marine species at the local level; i.e. respondents in the Azores valued changes in species richness in the waters around Pico and Faial islands while respondents in the Polish casestudy valued changes in species richness in the Gulf of Gdansk area. Overall each respondent was presented with 6 valuation questions. The concept of marginality is critical for economic analysis, yet quantifying a marginal change is not easy (Turner et al. 1998), especially for complex, interconnected and highly dynamic systems such as the marine environment. The first 2 levels of biodiversity loss proposed in this study (10 and $25 \%$ ) had already been tested in a previous analysis concerning preferences for different marine taxa (Ressurreição et al. 2011, 2012). A third level was introduced $(50 \%$ decline in species 
loss) in order to test human behaviour towards a drastic scenario of biodiversity loss mirroring current projections for marine systems (Myers \& Worm 2003, Worm et al. 2006, Jackson 2008).

\section{Information and photomontages}

Another issue that has remained troublesome in the CV literature concerns the level and depth of information conveyed to respondents (Spash 2002). Due to the scientific uncertainty surrounding the ecological impacts of species loss in the context of marine systems (Hooper et al. 2005, Worm et al. 2006, Bracken et al. 2008) no background information on the potential consequences of species declines was conveyed to the respondents. Participants were, therefore, stating values for different levels of species loss based upon their knowledge and their ability to pay. In these circumstances, stated WTP values may be expected to be lower than in an equivalent study where information was provided, as there is evidence that the provision of additional information about species can significantly raise public support for their conservation (Tkac 1998, Tisdell \& Wilson 2004, Tisdell et al. 2007)

Before the valuation exercise took place, respondents were informed regarding the number of species of fish and key marine taxa in order to provide an idea of the local biological diversity (specific to each location). Respondents were also informed about the number of species that hypothetically would be lost in fish and in key marine taxa under a scenario of 10, 25 and $50 \%$ reduction in species (Table 1 ). The presentation of the valuation scenarios was further supported by colour photomontages depicting several species of fish and other species representative of the local marine biodiversity (for an example of the photomontages used in the survey, see Ressurreição et al. 2011).

\section{Data analysis}

As a measure of theoretical validity, we tested the sensitivity in valuation responses to a change in the scope of the good (number of species lost) and examined whether the signs of the estimated coefficients in an econometric analysis were in accordance with theoretical expectations. Economic theory posits a positive relationship between the amount individuals are willing to pay and their ability to pay (typically proxied by respondents' income) and a further positive relationship between WTP and the level of use or importance respondents attribute to the good in question (see Desvousges et al. 1987, Ressurreição et al. 2011). Economically consistent measures of WTP are also expected to adjust with the scale of the change. Therefore, respondents are assumed to be able to distinguish between different quantities/ qualities of the good and reflect this variability in their valuation function (Smith \& Osborne 1996). Nonetheless, the demand curve is derived from the principle of diminishing marginal utility and implies that as the number of units consumed increase, the WTP for additional units of that good (i.e. marginal WTP) decreases (Rollins \& Lyke 1998). From the above and based on Bateman et al. (2005), we predict that theoretically consistent CV responses for different levels of species loss would behave according to the following hypothesis: (1) a positive yet diminishing marginal relationship between WTP and the number of marine species protected, (2) a positive relationship between the WTP and income, and (3) a positive relationship between WTP and the level of importance people attribute to marine biodiversity.

Data analysis followed the approach of Cameron \& Huppert (1989) and estimated $\log ($ WTP) from sociodemographic and attitudinal variables. Models were fitted using the survival package in $\mathrm{R}$ ( $\mathrm{R}$ Development Core Team 2008). By integrating social, economic or demographic characteristics of respondents such as gender, income or level of education, differences in WTP between groups could be evaluated. The modelling approach followed that of Ressurreição et al. (2012). In order to analyse the WTP for

Table 1. Numbers of species currently present and species that would be lost for each marine taxon and location under scenarios of 10, 25 and $50 \%$ loss. Note: total number of marine species is not yet fully assessed for the Azores and Gulf of Gdansk. To provide an idea of the biological diversity of each case study site, species richness of key marine taxa was conveyed to the respondents

\begin{tabular}{|lcccc|}
\hline Marine taxon & $\begin{array}{c}\text { Current } \\
\text { level }\end{array}$ & $\begin{array}{c}10 \% \\
\text { loss }\end{array}$ & $\begin{array}{c}25 \% \\
\text { loss }\end{array}$ & $\begin{array}{c}50 \% \\
\text { loss }\end{array}$ \\
\hline Azores (Portugal) & & & & \\
Fish & 520 & 52 & 130 & 260 \\
Marine mammals & 24 & 2 & 6 & 12 \\
Algae & 368 & 37 & 92 & 184 \\
Sea birds & 56 & 6 & 14 & 28 \\
Invertebrates & 1700 & 170 & 425 & 850 \\
Gulf of Gdansk (Poland) & & & & \\
Fish & 60 & 6 & 15 & 30 \\
Marine mammals & 4 & - & 1 & 2 \\
Algae & 42 & 4 & 10 & 21 \\
Sea birds & 125 & 13 & 31 & 63 \\
Invertebrates & 88 & 9 & 22 & 44 \\
\hline
\end{tabular}


marine species conservation in a cross-country perspective, we combined the data from the 2 casestudy sites. Individual bids and incomes were adjusted to 2008 US purchasing power using World Bank purchasing power parity (PPP) figures for private consumption. Visitors were adjusted by the PPP of their home country while residents were adjusted for the PPP where the survey took place.

In parallel to the formal econometric model, an exploratory analysis of the positive WTP responses into different categories of scope sensitivity was conducted along with an assessment of the motivations underlying CV responses.

\section{RESULTS}

\section{Empirical results and sample demographics}

A total of 747 surveys were completed resulting in $4482 \mathrm{CV}$ responses. Of the 747 respondents, 459 (61\%) were willing to pay to avoid species loss, while $288(39 \%)$ refused. Following debriefing, 125 (17\% of the total responses) of the refusals were considered protest responses and 163 (22\% of the total responses) genuine zero bidders. After excluding protest responses (Mitchell \& Carson 1989) and questionnaires with incomplete or inconsistent answers, $3636 \mathrm{CV}$ responses were suitable for analysis. Respondent demographics had a wide range in age, income level and professional occupations representative of the population of each case study (Table 2). While education and household size were comparable between case-study sites, income level represented the greatest contrast between respondents from the Azores islands and Gulf of Gdansk region (Azores \$3545, Gdansk \$1521; t-test on log(income) $\mathrm{p}<0.001$ ). In general, visitors had a higher level of income (visitors \$2996, residents $\$ 1773$, p < 0.001) and education (visitors 2.7, residents 2.5, p < 0.03) than residents, and participants were fairly evenly distributed among gender (47\% male, $53 \%$ female).

\section{Respondents' attitudes towards marine biodiversity}

Respondents in the Azores and in Gdansk held different attitudes towards marine biodiversity conservation. The demand for biodiversity conservation was highly pronounced in the Azores islands, where the overwhelming majority (85\% of the respondents) stated that they would like to see marine biodiversity conservation as a priority in the political agenda (compared with 39\% in Gdansk) and none of the respondents considered that marine biodiversity conservation was not important to them. In contrast, in Gdansk the majority of the respondents (54\%) considered marine biodiversity conservation important but not a priority (Table 3). Consistent with this result, the number of respondents willing to pay to prevent the loss of marine species at the local level was higher in the Azores (73\%) compared with Gdansk (56\%) (Table 4).

\section{Motivations underlying CV responses}

Motivations outlined by the respondents to justify positive WTP responses also followed a distinct pattern among case-study sites (Table 4). Use-motivations, based on the direct benefits received from marine biodiversity through food supply and recreational opportunities, were the most frequently cited reasons by respondents in Gdansk for wanting to pay for species conservation. In the Azores, bequest values (conservation for the benefit of future generations) were most important for positive WTP responses. Existence values (value independent of any human use or

Table 2. Socio-demographic profile of respondents detailed by case study site and broken down by residents and visitors. Education level: 1: elementary; 2: high school; 3: undergraduate; 4: postgraduate. Data are mean $\pm \mathrm{SD}$

\begin{tabular}{|c|c|c|c|c|c|c|c|c|c|c|c|}
\hline \multirow{2}{*}{$\begin{array}{l}\text { Respondent status } \\
\text { Azores }(\mathbf{n}=\mathbf{2 4 6})\end{array}$} & \multicolumn{3}{|c|}{ Monthly income (US \$) } & \multicolumn{2}{|c|}{ Household members } & \multicolumn{3}{|c|}{ Education level } & \multicolumn{3}{|c|}{ Age (yr) } \\
\hline & 3545 & \pm & 2267 & 2.7 & 1.1 & 2.6 & \pm & 0.8 & 38.2 & \pm & 12.9 \\
\hline Residents $(n=119)$ & 2662 & \pm & 1776 & 3.1 & 1.2 & 2.2 & \pm & 0.7 & 35.1 & \pm & 11.8 \\
\hline Visitors $(\mathrm{n}=127)$ & 4367 & \pm & 2370 & 2.4 & \pm 0.9 & 2.9 & \pm & 0.7 & 41.0 & \pm & 13.4 \\
\hline Gdansk $(n=501)$ & 1521 & \pm & 916 & 2.5 & 1.3 & 2.6 & \pm & 0.9 & 35.5 & \pm & 12.6 \\
\hline Residents $(n=376)$ & 1494 & \pm & 858 & 2.4 & 1.3 & 2.6 & \pm & 0.9 & 35.6 & \pm & 12.6 \\
\hline Visitors $(n=125)$ & 1604 & \pm & 1072 & 2.8 & 1.3 & 2.4 & \pm & 0.8 & 35.3 & \pm & 12.9 \\
\hline Total sample $(n=747)$ & 2186 & \pm & 1774 & 2.6 & 1.3 & 2.6 & \pm & 0.9 & 36.4 & \pm & 12.8 \\
\hline Residents $(\mathrm{n}=495)$ & 1773 & \pm & 1247 & 2.6 & 1.3 & 2.5 & \pm & 0.9 & 35.5 & \pm & 12.4 \\
\hline Visitors $(\mathrm{n}=252)$ & 2996 & \pm & 2303 & 2.6 & 1.2 & 2.7 & \pm & 0.8 & 38.2 & \pm & 13.5 \\
\hline
\end{tabular}


Table 3. Attitudes of respondents towards marine biodiversity (MB) conservation

\begin{tabular}{|lccc|}
\hline Respondent attitude & Azores & Gdansk & Total sample \\
\hline $\begin{array}{l}\text { MB conservation should } \\
\text { be a priority for governments } \\
\text { on a national and global level }\end{array}$ & $208(85 \%)$ & $196(39 \%)$ & $404(54 \%)$ \\
$\begin{array}{l}\text { MB conservation is important } \\
\text { but not a priority }\end{array}$ & $34(14 \%)$ & $271(54 \%)$ & $305(41 \%)$ \\
$\begin{array}{l}\text { I don't regard MB conservation } \\
\text { as important }\end{array}$ & $1(0 \%)$ & $18(4 \%)$ & $19(2.5 \%)$ \\
$\begin{array}{l}\text { I don't know } \\
\text { Total n }\end{array}$ & $3(1 \%)$ & $16(3 \%)$ & $19(2.5 \%)$ \\
& 246 & 501 & 747 \\
\hline
\end{tabular}

consumption) were the least quoted motivation for payments towards species preservation.

Overall, the Azores had the lowest proportion of non-WTP responses for marine species conservation. In both case-study sites most of the protest responses were based on the claim that marine biodiversity conservation is the government's responsibility, whereas genuine zero bidders were mostly justified by a lack of personal resources to pay for marine biodiversity conservation (Table 4 ).

\section{Positive WTP responses and responsiveness to scope}

As a first approach to assess how respondents respond to increased levels of marine species loss, we categorized positive WTP responses into 3 general classes of scope sensitivity: negative responsiveness to scope (i.e. giving less as the scope of change is made larger), insensitivity (i.e. invariant WTP) and positive responsiveness to scope (i.e. WTP increases with scope of the good). Scope-sensitive responses were further distinguished into 3 levels according to the magnitude of responsiveness. The results presented in Table 5 are the proportion of respondents that showed one of the classes of scope sensitivity in view of a decrease in species richness from 10 to $25 \%$ and then from 25 to $50 \%$. In both case studies the majority of respondents were responsive to scope. A large minority of respondents ( 36 to $46 \%$ ) was not responsive to scope, stating the same amount for the different

Table 4. Motivations of respondents underlying contingent valuation responses. WTP: willingness to pay; MB: marine biodiversity

\begin{tabular}{|c|c|c|c|}
\hline Respondent motivation & Azores & Gdansk & Total sample \\
\hline WTP & $179(73 \%)$ & $280(56 \%)$ & $459(62 \%)$ \\
\hline No WTP & $67(27 \%)$ & $221(44 \%)$ & $288(39 \%)$ \\
\hline Total $\mathbf{n}$ & 246 & 501 & 747 \\
\hline Protest responses (total) ${ }^{\mathrm{a}}$ & $44(18 \%)$ & $81(16 \%)$ & $125(17 \%)$ \\
\hline Government's responsibility & 37 & 58 & 95 \\
\hline Insufficient information & 1 & 16 & 17 \\
\hline Refusal to put a price on $\mathrm{MB}$ & 1 & 4 & 5 \\
\hline Objection towards the valuation question & 3 & 1 & 4 \\
\hline Other reasons & 2 & 2 & 4 \\
\hline Genuine zero bidders (total) ${ }^{a}$ & $23(9 \%)$ & $140(28 \%)$ & $163(22 \%)$ \\
\hline Can't afford to pay & 13 & 79 & 92 \\
\hline Society has more important problems & 6 & 37 & 43 \\
\hline Insufficient benefit of such a payment & 4 & 24 & 28 \\
\hline Positive WTP (total) ${ }^{\mathrm{b}}$ & $179(73 \%)$ & $280(56 \%)$ & $459(62 \%)$ \\
\hline $\begin{array}{l}\text { Direct use value: MB of this region provide an option for leisure, } \\
\text { food provision and it is important for the local economy }\end{array}$ & 123 & 195 & 318 \\
\hline $\begin{array}{l}\text { Indirect use value: MB of this region is precious and it benefits human } \\
\text { wellbeing (e.g. water quality, erosion control, coastal protection) }\end{array}$ & 108 & 91 & 199 \\
\hline $\begin{array}{l}\text { Existence value: I enjoy knowing that MB exists in this region even } \\
\text { if I never see or use it }\end{array}$ & 96 & 88 & 184 \\
\hline $\begin{array}{l}\text { Option value: The MB of this region has the right to exist even if it } \\
\text { does not appear important to human wellbeing today }\end{array}$ & 111 & 146 & 257 \\
\hline $\begin{array}{l}\text { Bequest value: I enjoy knowing that the future generations will be able } \\
\text { to enjoy } \mathrm{MB} \text { of this region }\end{array}$ & 152 & 188 & 340 \\
\hline Other reasons & 14 & 2 & 16 \\
\hline
\end{tabular}


Table 5. Categorization of respondents' willingness to pay (WTP) bids according to 3 classes of scope sensitivity of marine species loss

\begin{tabular}{|lcccc|}
\hline $\begin{array}{l}\text { Responsiveness } \\
\text { to scope }\end{array}$ & \multicolumn{2}{c}{$\begin{array}{c}\text { Azores } \\
\text { (\% respondents) } \\
25 \% \text { loss }\end{array}$} & $50 \%$ loss & $\begin{array}{c}\text { Gdansk } \\
\text { (\% respondents) }\end{array}$ \\
\hline Fish loss & $50 \%$ loss \\
Negative & & & & \\
Insensitive & 0 & 0 & 2 & 3 \\
Positive (total) & 44 & 40 & 44 & 37 \\
$\quad$ Less than twice & 26 & 60 & 54 & 60 \\
$\quad$ Twice & 18 & 14 & 32 & 41 \\
$\quad$ More than twice & 12 & 16 & 14 & 10 \\
All marine taxa & & & 8 & 9 \\
Negative & 0 & 0 & 1 & 2 \\
Insensitive & 41 & 36 & 46 & 39 \\
Positive (total) & 59 & 64 & 53 & 59 \\
$\quad$ Less than twice & 29 & 34 & 35 & 39 \\
$\quad$ Twice & 18 & 16 & 10 & 15 \\
$\quad$ More than twice & 12 & 14 & 8 & 5 \\
\hline
\end{tabular}

among the different levels of species loss $(10$, 25 and $50 \%$ ) both for fish and all marine species. Furthermore, respondents were willing to pay more to prevent losses in all marine species than to prevent only losses in species of fish, i.e. respondents were willing to pay more to protect the whole species assemblage rather than a specific part of the ecosystem. In general respondents in the Azores were willing to pay significantly more to prevent losses in marine species than respondents in the Gulf of Gdansk region (Table 6). This result is consistent with both the higher number of species that would be lost under a hypothetical scenario of 10,25 or $50 \%$ decline in species richness, and the higher level of importance attributed to marine biodiversity conservation by the respondents in the Azores.

valuation scenarios. Very few (0 to $3 \%$ ) showed a negative response to scope (Table 5).

During the course of the valuation exercise, respondents were encouraged to justify their responses. Among the respondents who decreased their WTP bids when faced with an increased scenario of species loss, a common statement was 'in a scenario of species decline the government should take the lead role to halt biodiversity loss'. Several reasons were given by the respondents to justify their invariant WTP to prevent different levels of species loss. While some individuals exhibited clearly charitable behaviour (e.g. 'I'm contributing to the prevention of species loss and the level [of that loss] is irrelevant'), others were constrained by a fixed limit of expendable income and stated, 'I'm giving the same because of budget constraints' or 'In this moment this is all I can afford'. Non-scope-sensitive responses were also justified by a lack of awareness regarding the ecological impacts of losing one or more species. In this context, statements that were expressed frequently to justify invariant WTP were 'losing one species can be as bad as losing more' or 'I don't know what would be the impacts of losing several species in the sea'

\section{WTP modelling and scope tests}

WTP for different levels of marine species loss were regressed on a set of demographic and attitudinal variables according to the hypothesis in the 'Data analysis' section (Table 6). The regression results showed that WTP was an increasing function of the decline in species and significantly different
Regarding socio-demographic variables, log(income) had a positive and highly significant effect on $\log ($ WTP), while an increase in the number of household members decreased WTP. The highest level of education substantially increased WTP. Students, the retired and the unemployed were likely to pay less for species conservation than other employment categories. As found in previous studies (Ressurreição et al. 2011), for a given income, residents were willing to pay more than visitors lending support to the hypothesis that local identity and place attachment make a compelling case for marine biodiversity stewardship (Table 6). Finally, respondents that engaged in positive environmental behaviours or attitudes tended to give higher values for marine biodiversity than non-environmentalists. This also holds for respondents who regarded the conservation of marine biodiversity as a priority compared to those who did not attribute such a higher rank to this cause.

\section{WTP values for hypothetical scenarios of loss in marine species}

Predicted one-off mean WTP values are presented in USD (\$), normalised against US purchasing power and broken down between residents and visitors (Table 7). Note that unlike the regression analysis, WTP are summaries of actual bids and not controlled for income differences.

Overall positive and responsive-scope values were allocated to prevent different scenarios of marine species loss from the status quo in both locations. Respondents in the Azores allocated much higher 
Table 6. Factors influencing the willingness to pay (WTP) responses to avoid 3 levels of marine species loss. Survey questionnaire is available at www.int-res.com/articles/suppl/m467p015_supp.pdf. Significant values: ${ }^{* * *} \mathrm{p}<0.01,{ }^{* *} \mathrm{p}<0.05,{ }^{*} \mathrm{p}<0.1$

\begin{tabular}{|c|c|c|c|c|}
\hline \multicolumn{2}{|l|}{$\begin{array}{l}\text { Dependent variable: WTP to prevent a de } \\
\text { Number of observations: } 3636 \\
\text { Log-likelihood model: }-10023.1 \\
\text { Log-likelihood (intercept only): }-10847.8 \\
\text { Log normal distribution }\end{array}$} & \multicolumn{3}{|c|}{$\begin{array}{c}\mathrm{X}^{2}=1649.49 \\
\mathrm{df}=32 \\
\mathrm{p}=0 \\
\text { scale }=2.36\end{array}$} \\
\hline Variable labels & Parameter estimates & SE & $Z$ & $\mathrm{p}$ \\
\hline Intercept & -3.7448 & 0.8478 & -4.4170 & $<0.0001^{* * *}$ \\
\hline $25 \%$ level of species loss $(1,0)$ & 0.2210 & 0.1000 & 2.2110 & $0.0270^{* *}$ \\
\hline $50 \%$ level of species loss $(1,0)$ & 0.4360 & 0.1004 & 4.3420 & $<0.0001^{* * *}$ \\
\hline Gdansk & -0.8378 & 0.1441 & -5.8150 & $<0.0001^{* * *}$ \\
\hline All marine species & 0.6483 & 0.1418 & 4.5700 & $<0.0001^{* * *}$ \\
\hline Log PPP monthly income (US \$) & 0.9960 & 0.0804 & 1.23930 & $<0.0001^{* * *}$ \\
\hline Male/female $(1,0)$ & -0.1428 & 0.0866 & -1.6500 & $0.0989^{*}$ \\
\hline Public employee & -0.3600 & 0.3596 & -1.0010 & 0.3170 \\
\hline Private employee & 0.0193 & 0.3573 & 0.0540 & 0.9570 \\
\hline Self employed & -0.1960 & 0.3642 & -0.5380 & 0.5900 \\
\hline Student & -1.2154 & 0.3860 & -3.1490 & $0.0016^{* * *}$ \\
\hline Retired & -1.7359 & 0.4286 & -4.0500 & $0.0001^{* * *}$ \\
\hline Unemployed & -1.7813 & 0.4427 & -4.0240 & $0.0001^{* * *}$ \\
\hline Homemaker & -0.3086 & 0.4029 & -0.7660 & 0.4440 \\
\hline Household - linear term & -0.5485 & 0.1450 & -3.7830 & $0.0002^{* * *}$ \\
\hline Household - quadratic term & 0.0750 & 0.0234 & 3.2020 & $0.0014^{* * *}$ \\
\hline Age - linear term & 0.0272 & 0.0237 & 1.1450 & 0.2520 \\
\hline Age - quadratic term & -0.0002 & 0.0003 & -0.7650 & 0.4440 \\
\hline Resident/visitor condition $(1,0)$ & 0.5182 & 0.0923 & 5.6170 & $<0.0001^{* * *}$ \\
\hline Biodiversity not priority & -0.4083 & 0.0935 & -4.3670 & $<0.0001^{* * *}$ \\
\hline Biodiversity not important & -3.0760 & 0.3607 & -8.5270 & $<0.0001^{* * *}$ \\
\hline Don't know & -4.0345 & 0.3701 & -1.0900 & $<0.0001^{* * *}$ \\
\hline Education - linear term & -1.7036 & 0.3528 & -4.8280 & $<0.0001^{* * *}$ \\
\hline Education - quadratic term & 0.3146 & 0.0618 & 5.0940 & $<0.0001^{* * *}$ \\
\hline Read/ TV env. conservation $(1,0)$ & 1.2049 & 0.1161 & 1.0374 & $<0.0001^{* * *}$ \\
\hline Recycling household goods $(1,0)$ & 0.3506 & 0.0979 & 3.5830 & $0.0003^{* * *}$ \\
\hline Subscribing to a magazine $(1,0)$ & 0.2462 & 0.1343 & 1.8330 & $0.0668^{*}$ \\
\hline Purchasing ecofriendly products $(1,0)$ & 0.1110 & 0.0923 & 1.2030 & 0.2290 \\
\hline Donating to charities $(1,0)$ & 1.0334 & 0.1239 & 8.3410 & $<0.0001^{* * *}$ \\
\hline Actively campaigning $(1,0)$ & 0.0953 & 0.1599 & 0.5960 & 0.5510 \\
\hline Membership of conserv. group $(1,0)$ & -0.1318 & 0.1832 & -0.7190 & 0.4720 \\
\hline Interaction factor: $\mathrm{MB} \times$ Gdansk & -0.3970 & 0.1737 & -2.2860 & $0.0223^{* *}$ \\
\hline $\log ($ scale $)$ & 0.8571 & 0.0149 & 5.7528 & $<0.0001^{* * *}$ \\
\hline
\end{tabular}

values to avoid marine species loss at the local level relative to respondents in the Gulf of Gdansk region. As an example, in the Azores for the valuation of fish the one-off mean WTP values ranged from $\$ 234$ (to prevent a $10 \%$ loss) to $\$ 648$ (to prevent $50 \%$ loss), while in Gdansk the WTP figures (for the same scope gradient) ranged from $\$ 34$ to $\$ 99$. The WTP values to prevent losses in all species in the Azores were accordingly twice the values attributed to prevent losses in the species of fish alone. In Gdansk these differences were less pronounced. A brief conclusion one can draw from this analysis is while the data passed the Bateman tests and responsiveness to scope was found, there was a marked diminishing marginal value per additional species protected (Fig. 1).

\section{DISCUSSION}

Unlike most valuation studies involving marine species and scope tests, essentially based on single and charismatic species, this CV study adopts an ecosystem approach to species valuation and conservation. Whilst the importance of taking such an approach is well documented in the ecology literature, the economic implications have been less thoroughly addressed (Fleming \& Alexander 2003). Furthermore, with the exceptions of Jin et al. (2010), which adopts a cross-country approach to value marine turtle conservation, and more recently Ressurreição et al. (2012), which evaluates relative preferences for marine taxa, previous studies have been geographi- 
Table 7. Respondents' willingness to pay (WTP) point estimates for 3 scenarios of species loss, broken down by residents and visitors. MB: marine biodiversity

\begin{tabular}{|c|c|c|c|c|c|c|c|c|}
\hline \multirow[t]{2}{*}{ Taxon } & \multirow[t]{2}{*}{ Location } & \multirow{2}{*}{$\begin{array}{l}\text { Level of } \\
\text { loss (\%) }\end{array}$} & \multicolumn{2}{|c|}{ Median WTP (US \$) } & \multicolumn{2}{|c|}{ Mean WTP (US \$) } & \multicolumn{2}{|c|}{ WTP vs. household income (\% } \\
\hline & & & Residents & Visitors & Residents & Visitors & Residents & Visitors \\
\hline \multirow[t]{6}{*}{ Fish } & \multirow[t]{3}{*}{ Azores } & 10 & 38 & 66 & 234 & 406 & 8.79 & 9.30 \\
\hline & & 25 & 48 & 83 & 296 & 510 & 11.13 & 11.6 \\
\hline & & 50 & 60 & 106 & 366 & 648 & 13.78 & 14.8 \\
\hline & \multirow[t]{3}{*}{ Gdansk } & 10 & 11 & 6 & 64 & 34 & 4.32 & 2.15 \\
\hline & & 25 & 13 & 7 & 80 & 43 & 5.37 & 2.68 \\
\hline & & 50 & 16 & 8 & 99 & 49 & 6.66 & 3.03 \\
\hline \multirow[t]{6}{*}{ MB } & \multirow[t]{3}{*}{ Azores } & 10 & 73 & 127 & 449 & 777 & 16.90 & 17.79 \\
\hline & & 25 & 93 & 159 & 569 & 975 & 21.40 & 22.32 \\
\hline & & 50 & 115 & 203 & 704 & 1239 & 26.50 & 28.37 \\
\hline & \multirow[t]{3}{*}{ Gdansk } & 10 & 14 & 7 & 83 & 44 & 5.55 & 2.76 \\
\hline & & 25 & 17 & 9 & 103 & 55 & 6.90 & 3.44 \\
\hline & & 50 & 21 & 10 & 128 & 62 & 8.56 & 3.89 \\
\hline
\end{tabular}

cally specific. In contrast, the present study aimed at estimating and comparing people's marginal values associated with increased levels of species loss in 2 contrasting marine regions in Europe: the Gulf of Gdansk region (Poland, Baltic Sea) and the Azores islands (Portugal, North East Atlantic).

The complex and transboundary nature of the marine environment calls for adaptive and cooperative management (De Santo 2010). By using 2 casestudy sites, this study allowed examination of how citizens of different European countries perceive and value marine biodiversity changes, thereby providing relevant policy insights. Our results showed that in general respondents attached positive and significant values to the conservation of marine species, but that respondents in different locations valued and perceived marine biodiversity differently. Respondents in the Azores demonstrated a comparatively higher demand for marine biodiversity conservation than respondents in Gdansk. They also allocated significantly higher values to prevent marine species loss at the local level compared with the respondents in the Polish case-study. This result seems to be driven by an income effect (respondents in Azores were wealthier comparatively to Gdansk), yet there is evidence to suggest that the specific maritime culture of each location has a significant role in shaping people's values for biodiversity conservation. As an isolated ar-

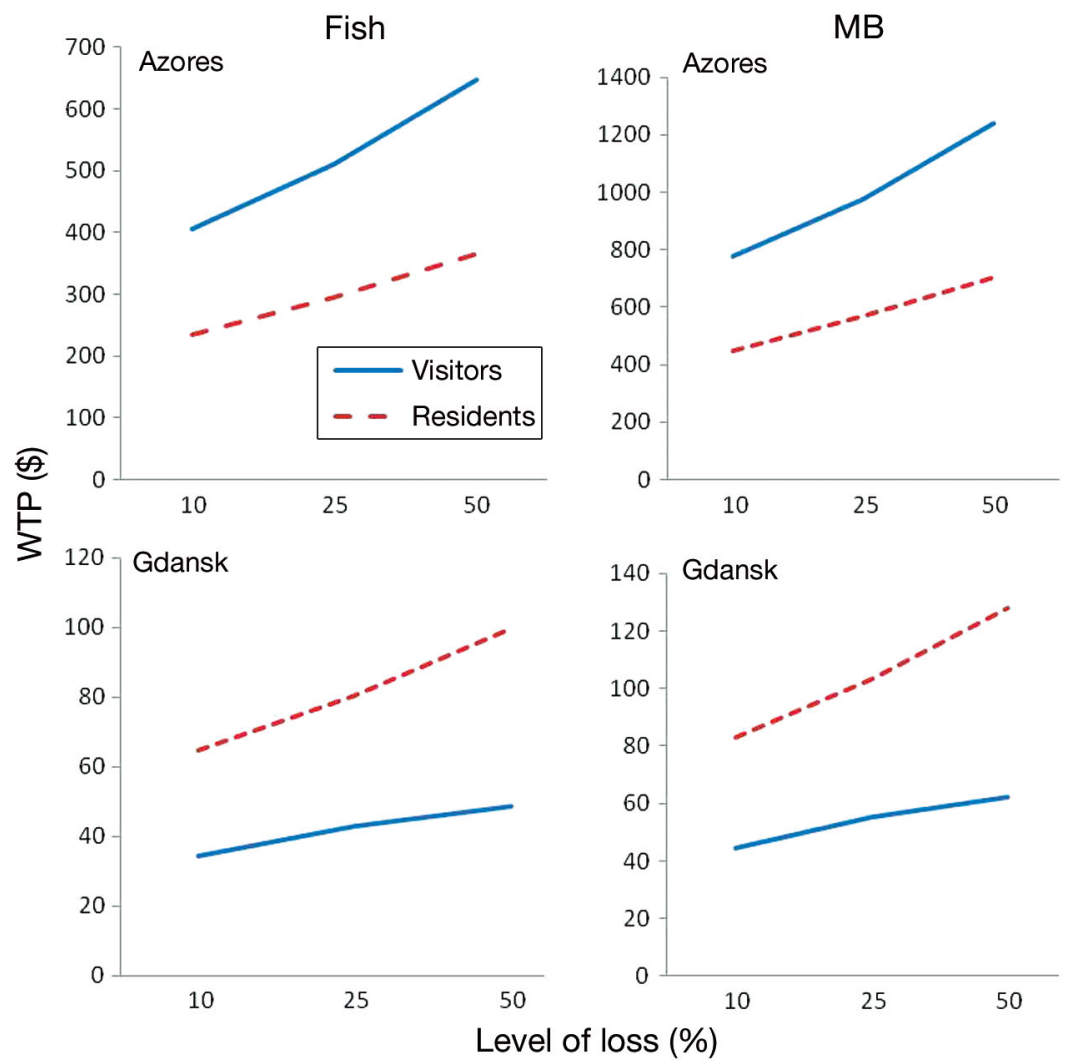

Fig. 1. Respondents' willingness to pay (WTP) point estimates for 3 scenarios of marine species loss detailed by case-study sites and broken down by visitors and residents. MB: marine biodiversity

chipelago with a considerable marine conservation interest and with a significant part of the economy based on the sea (e.g. fisheries, tourism), it is not surprising that respondents in the Azores feel more engaged with the marine environment and perceived more clearly the role of the seascape in their livelihood, wellbeing and cultural identity, relative to re- 
spondents in Gdansk. In fact, the seascape and associated activities are an intrinsic component of the Azorean lifestyle and an important part of its touristic appeal. Examples include big game and recreational fishing, sailing, SCUBA diving and whale watching. Azoreans close connection with the sea is also reflected in their cultural and religious traditions. The Whaler's Week Festival, August Tide Festival and the renowned Sea Week - dedicated primarily to marine sports - are just a few examples of the many seafocused festivals that take place in many towns and villages of the islands throughout the year. Regional differences in absolute values and relative preferences towards marine biodiversity have also been found in an earlier study (Ressurreição et al. 2012). Taken together, these results underscore the need to adapt conservation policies taking into account the diversity of preferences and developing ecosystembased approaches that reflect the regional ecological and cultural diversity within Europe.

Understanding the values and attitudes of the various users for marine biodiversity is also key for policy design. Econometric evidence suggested that when comparing residents and visitors with similar sociodemographic profiles, residents were more likely to attach higher values to prevent species loss at the local level compared to visitors, highlighting the importance of these stakeholders in the governance of marine systems. Higher values to protect marine biodiversity were also found among visitors, especially in the Azores case study. In the past few years the tourism industry in the Azores has gained a new impetus and the islands have become a high-profile destination for sustainable tourism 1 . In contrast to the Polish case-study, visitors to the Azores are generally high income foreigners seeking marine eco-touristic attractions, thus having a large recreational component of their total economic value to preserve marine species. Overall, these results suggest that societal values for marine biodiversity can be highly dependent on specific socio-ecological contexts and call for further understanding of the interplay between stakeholders and their environment at the local, national and EU level.

To be able to apply the ecosystem approach and measures of economic valuation to guide policy, it is also important to understand how individuals per-

\footnotetext{
1In 2008 the Azores archipelago was ranked second by National Geographic Traveller Magazine in the top 5 island destinations in the world for sustainable tourism, and received other international recognition by e.g. the BootsnALL, World Travel Guide, European Commission (EDEN prize)
}

ceive and value marine changes. The marine environment is a complex assemblage of unfamiliar environmental goods; hence, there is a strong need to demonstrate that people's values for such goods are valid, consistent and useful. Overall we found that the scope tests were passed successfully, i.e. the regression results showed that WTP was an increased function of species richness decline and WTP was significantly different between increased levels of marine species loss $(10,25$ and $50 \%)$ both for fish and all marine species. Furthermore, respondents were willing to pay more to prevent loss in all marine species than to prevent losses in species of fish alone. Higher WTP was found among wealthier respondents, the respondents who considered that marine biodiversity should be a priority for governments at local and global scale and among respondents stating higher environmental awareness and commitment; suggesting therefore that $\mathrm{CV}$ responses were not merely symbolic.

While there is evidence that the majority of respondents behaved as rational economic actors, it is also important to consider the magnitude of the scope sensitivity. Taking as an example the visitors' demand curve for fish conservation in the Azores, there is a marked diminishing marginal value per additional species protected. For the first level of decline, the mean value to prevent the extinction of fish species was $\$ 7.81$ per species, while at the second level of decline the value decreased to $\$ 3.92$, and for the last level, to $\$ 2.49$ per species. Diminishing marginal values per additional unit of good used or consumed are expected under the framework of economic analysis as marginal utility usually decreases as total consumption increases (Rollins \& Lyke 1998), and no guidelines exist in the literature as to how much scope is acceptable in a CVM study (Jin et al. 2010). Nonetheless, it can be argued that these differences are not economically plausible and that the validity of the CV results is disputed.

We argue that rather than looking at face values, it is as important to understand the motivations behind those values. Evidence from this and other studies shows that people hold pluralistic values towards complex goods as biodiversity and some of those are non-economic values (Spash et al. 2009). Indeed, preserving species for the benefit of future generations was the most frequently cited reason for wanting to pay to preserve marine biodiversity. This result portrays a societal position embedded in ethics and emphasises the relevance of non-use values in the valuation of complex environmental amenities. The interpretation of environmental values requires, there- 
fore, broadening our view beyond the dogmatic lens of economic analysis, and highlighting the importance of combining other bodies of knowledge with WTP results to understand human values and attitudes towards biodiversity conservation. Furthermore, understanding what drives people towards marine biodiversity conservation provides important insights with respect to effective communication of ideas about ecosystem services both to decision makers and people more generally, and to adjusting the content of those messages to reach specific audiences.

What is 'rational' in light of economic or psychological behaviour may not be rational in an ethical perspective or the most meaningful approach ecologically speaking, and our results showed that the demand curve for biodiversity conservation encompasses all those dimensions. Besides, all these aspects (e.g. ethics, altruism, rationality) are needed in order to move towards better environmental quality by changing human behaviour, and in order to understand our environmental values and their role in our wellbeing as individuals and social beings (Spash \& Biel 2002). Instead of simply dismissing CV studies (or ultimately stated preference methods) based on scope tests results, a step forward in understanding human behaviour intentions - such as stated WTP — would be to use the observations made in valuation studies to improve choice theory and highlight inconsistencies (Vatn 2004). As noted by Portney (1994) the critical analysis directed at the CVM over the past decades has improved our understanding about cognitive processes, rationality and the nature of human preferences for all goods, public and private.

Using the empirical results of this CV study, several categories of motivations can be distinguished for different responsiveness to scope. While the importance of factors such as charitable behaviour or 'warm glow' have been widely debated in the CV literature (Chilton \& Hutchinson 2000, Nunes \& Schokkaert 2003), the analysis of the public's lack of awareness about the consequences of biodiversity changes, and the welfare trade-offs involved, remains less conspicuous. This CV study shows that people do care about marine biodiversity loss and are resistant to decreases from the status quo; however, how these changes link to human wellbeing remains unclear to public perception. Respondents commonly refer to uncertainties about the implications of losing one or several species to justify insufficient or lack of scope in the stated WTP. In this case, public uncertainty is also echoed by scientific uncertainty. After decades of ecological research the real-world consequences of declining biodiversity are not yet fully understood and are particularly enigmatic for the world's oceans, which are functionally complex and ecologically interdependent making it difficult to predict their dynamics in any detail or scale (Schröter et al. 2005, Worm et al. 2006).

One of the major challenges posed to the EU's environmental policy in the forthcoming decades is to improve biodiversity conservation and to attain 'good environmental status' for its regional seas. Enabling ecosystem-based management on a European, national and regional level and managing the long-term delivery of ecosystem services requires assessing which species and services are most valuable both to ecosystems and to people. Combining ecosystem services research with socio-economic analysis provides one way to move towards a more structured engagement between what is socially and ecologically desired of marine management and to achieve more efficient, equitable and sustainable outcomes (Barbier et al. 2008, Fisher et al. 2008). In spite of methodological limitations and significant knowledge gaps in our understanding of ecosystem dynamics, valuation techniques such as the CVM (if used correctly) provide powerful tools to assess the value of specific ecosystem or biodiversity benefits, and to identify and understand people's values and attitudes towards biodiversity conservation. Nonetheless, economic analysis should not be the only input into conservation decisions. People can and do value marine biodiversity conservation based on a range of other criteria such as for ethical, cultural or historical reasons, and we need to understand all these drivers in order to understand human behaviour. Meeting the research needs underpinning ecosystem-based management requires rethinking traditional paradigms by using an integrated and interdisciplinary approach. It also involves a new framing of management tasks making allowances for social, political and cultural diversity across nations and a greater investment in sharing knowledge and information where the scientific community must play a leading role. Communicating knowledge on ecosystem research based on the most recent scientific evidence and incorporating socio-economic considerations is critical to promote public ocean literacy and to move towards a more committed stewardship of marine biodiversity. However, scientists must provide more than just well studied and precise information. To capture the interest of the public and spur action among policy makers, ecosystem science must be shared in publicly accessible formats and extend beyond the status of species and habitats to explain 
the links between biodiversity loss and human wellbeing so that politicians and citizens understand the economic and ecological consequences of not working towards marine biodiversity conservation.

Acknowledgements. The authors dedicate this paper to the memory of our co-author, friend and collaborator Gareth Edwards-Jones, who died on 14 August 2011 aged 49. Financial support of the Portuguese Foundation for Science and Technology (PhD grant SFRH/ BD/31286/2006 to A.R.), of the Polish Ministry of Science and Higher Education (PhD grant N305232835 to T.Z.) and the project 'Innodoktorant - Scholarships for PhD students' is gratefully acknowledged. IMARDOP/UAz (research and Development Unit \#531) and LARSyS-Associated Laboratory are supported by FCT (under the strategic project OE, COMPETE, QREN) and by DRCTCGR Azores through a Pluriannual Funding scheme. The authors acknowledge the input at an early stage of this research provided by the MarBEF theme III members. We are also thankful to I. Kamińska and K. Brzeska for their help in data collection and to the 747 respondents who took the time to answer the questionnaire survey. Finally, the authors are grateful to the editor and several anonymous reviewers for their careful reading and thoughtful comments on previous versions of this manuscript.

\section{LITERATURE CITED}

Arrow K, Solow R, Portney P, Leamer E, Radner R, Schuman $\mathrm{H}$ (1993) Report of the NOAA panel on contingent valuation. US Fed Regist 58:4602-4614

Barbier EB, Koch EW, Silliman BR, Hacker SD and others (2008) Coastal ecosystem-based management with nonlinear ecological functions and values. Science 319: 321-323

Bateman IJ, Cooper P, Georgiou S, Navrud S and others (2005) Economic valuation of policies for managing acidity in remote mountain lakes: examining validity through scope sensitivity testing. Aquat Sci 67:274-291

Bosetti V, Pearce D (2003) A study of environmental conflict: the economic value of grey seals in southwest England. Biodivers Conserv 12:2361-2392

- Bracken M, Friberg S, Gonzalez-Dorantes C, Williams S (2008) Functional consequences of realistic biodiversity changes in a marine ecosystem. Proc Natl Acad Sci USA 105:924-928

> Cadotte MW, Cardinale BJ, Oakley TH (2008) Evolutionary history and the effect of biodiversity on plant productivity. Proc Natl Acad Sci USA 105:17012-17017

> Cameron TA, Huppert DD (1989) OLS versus ML estimation of non-market resource values with payment card interval data. J Environ Econ Manage 17:230-246

> Carpenter SR, DeFries R, Dietz T, Mooney HA, Polasky S, Reid WV, Scholes RJ (2006) Millennium ecosystem assessment: research needs. Science 314:257-258

Carpenter SR, Mooney HA, Agard J, Capistranod D and others (2009) Science for managing ecosystem services: beyond the millennium ecosystem assessment. Proc Natl Acad Sci USA 106:1305-1312

Carson RT, Mitchell RC (1995) Sequencing and nesting in contingent valuation surveys. J Environ Econ Manag 28:155-173
Chee Y (2004) An ecological perspective on the valuation of ecosystem services. Biol Conserv 120:549-565

Chilton SM, Hutchinson WG (2000) A note on the warm glow of giving and scope sensitivity in contingent valuation studies. J Econ Psychol 21:343-349

Coll M, Piroddi C, Steenbeek J, Kaschner K and others (2010) The biodiversity of the Mediterranean Sea: estimates, patterns, and threats. PLoS ONE 5:e11842

Cornell S (2010) Valuing ecosystem benefits in a dynamic world. Clim Res 45:261-272

De Santo E (2010) Whose science? Precaution and powerplay in European marine environmental decision-making. Mar Policy 34:414-420

> Desvousges WH, Smith VK, Fisher A (1987) Option price estimates for water quality improvements: a contingent valuation study for the Monongahela River. J Environ Econ Manage 14:248-267

Eurobarometer (2010) Attitudes of Europeans towards the issue of biodiversity. Flash Eurobarometer 290, Gallup Hungary, Budapest

Fischer A, Hanley N (2007) Analysing decision behaviour in stated preference surveys: a consumer psychological approach. Ecol Econ 61:303-314

Fisher B, Turner K, Zylstra M, Brouwer R and others (2008) Ecosystem services and economic theory: integration for policy-relevant research. Ecol Appl 18:2050-2067

> Fleming CM, Alexander RR (2003) Single-species versus multiple-species models: the economic implications. Ecol Model 170:203-211

> Glasby GP, Szefer P (1998) Marine pollution in Gdansk Bay, Puck Bay and the Vistula Lagoon, Poland: an overview. Sci Total Environ 212:49-57

HELCOM (2009) Biodiversity in the Baltic Sea: an integrated thematic assessment on biodiversity and nature conservation in the Baltic Sea. Balt Sea Environ Proc 116B

Hooper DU, Chapin FS, Ewel JJ, Hector A and others (2005) Effects of biodiversity on ecosystem functioning: a consensus of current knowledge. Ecol Monogr 75:3-35

Jackson J (2008) Ecological extinction and evolution in the brave new ocean. Proc Natl Acad Sci USA 105:1145811465

> Jin J, Indab A, Nabangchang O, Thuy TD, Harder D, Subade RF (2010) Valuing marine turtle conservation: a cross-country study in Asian cities. Ecol Econ 69: 2020-2026

Kruk-Dowgiałło L, Szaniawska A (2008) Gulf of Gdańsk and Puck Bay. Part IIB Eastern Baltic coast. In: Schewier U (eds) Ecology of Baltic coastal waters. Ecological Studies 197, Springer-Verlag, Berlin, p 139-162

> Langford IH, Kontogianni A, Skourtos MS, Georgiou S, Bateman IJ (1998) Multivariate mixed models for openended contingent valuation data: willingness to pay for conservation of monk seals. Environ Resour Econ 12: 443-456

Layton D, Brown G, Plummer M (2001) Valuing multiple programs to improve fish populations. Washington State Department of Ecology, Seattle, WA

> Loomis JB, White DS (1996) Economic benefits of rare and endangered species: summary and meta-analysis. Ecol Econ 18:197-206

Majewski A (1994) Natural environmental conditions of the Gulf of Gdańsk and its coastline. In: Błażejowski J, Schuller D (eds) The pollution and renewal of the Gulf of Gdańsk, Mater Seminar. University of Gdańsk, Gdynia, p 22-35 
Martín-López B, Montes C, Benayas J (2008) Economic valuation of biodiversity conservation: the meaning of numbers. Conserv Biol 22:624-635

Mee LD, Jefferson RL, Laffoley DA, Elliott M (2008) How good is good? Human values and Europe's proposed Marine Strategy Directive. Mar Pollut Bull 56:187-204

Menezes GM, Sigler MF, Silva HM, Pinho MR (2006) Structure and zonation of demersal fish assemblages off the Azores Archipelago (mid-Atlantic). Mar Ecol Prog Ser 324:241-261

Mitchell RC, Carson RT (1989) Using surveys to value public goods: the contingent valuation method. Resources for the Future, Washington, DC

Mooney H, Mace G (2009) Biodiversity policy challenges. Science 325:1474

Morato T, Watson R, Pitcher TJ, Pauly D (2006) Fishing down the deep. Fish Fish 7:24-34

- Myers R, Worm B (2003) Rapid worldwide depletion of predatory fish communities. Nature 423:280-283

> Nunes P, Schokkaert E (2003) Identifying the warm glow effect in contingent valuation. J Environ Econ Manag 45: 231-245

OSPAR (2010) Quality status report 2010. OSPAR Comission, London

Pandolfi JM, Jackson JB, Baron N, Bradbury RH and others (2005) Are US coral reefs on the slippery slope to slime? Science 307:1725-1726

Portney PR (1994) The contingent valuation debate: why economists should care. J Econ Perspect 8:3-17

Pullin A, Baldi A, Can OE, Dieterich E and others (2009) Conservation focus on Europe: major conservation policy issues that need to be informed by conservation science. Conserv Biol 23:818-824

R Development Core Team (2008) R: a language and environment for statistical computing. R Foundation for Statistical Computing, Vienna, available at: www.R-project.org

Ressurreição A, Gibbons J, Dentinho T, Kaiser M, Santos SS, Edwards-Jones G (2011) Economic valuation of species loss in the open sea. Ecol Econ 70:729-739

Ressurreição A, Gibbons J, Kaiser M, Dentinho T and others (2012) Different cultures, different values: the role of cultural variation in public's WTP for marine species conservation. Biol Conserv 145:148-159

Richardson L, Loomis J (2009) The total economic value of threatened, endangered and rare species: an updated meta-analysis. Ecol Econ 68:1535-1548

Rollins K, Lyke A (1998) The case for diminishing marginal existence values. J Environ Econ Manag 36:324-344

Schröter D, Cramer W, Leemans R, Prentice C and others (2005) Ecosystem service supply and vulnerability to global change in Europe. Science 310:1333-1337

Smith VK, Osborne LL (1996) Do contingent valuation estimates pass a 'scope' test? A meta-analysis. J Environ Econ Manage 31:287-301

Editorial responsibility: Martin Solan,

Southampton, UK
Spash CL (2002) Informing and forming preferences in environmental valuation: coral reef biodiversity. J Econ Psychol 23:665-687

Spash CL, Biel (2002) Social psychology and economics in environmental research. J Econ Psychol 23:551-555

Spash CL, Urama K, Burton R, Kenyon W, Shannon P, Hill G (2009) Motives behind willingness to pay for improving biodiversity in a water ecosystem: economics, ethics and social psychology. Ecol Econ 68:955-964

$>$ Subade R (2007) Mechanisms to capture economic values of marine biodiversity: the case of Tubbataha Reefs UNESCO world heritage site, Philippines. Mar Policy 31: $135-142$

Sutherland WJ, Adams WM, Aronson RB, Aveling R and others (2009) One hundred questions of importance to the conservation of global biological diversity. Conserv Biol 23:557-567

Symes D, Hoefnagel E (2010) Fisheries policy, research and the social sciences in Europe: challenges for the 21st century. Mar Policy 34:268-275

TEEB (The Economics of Ecosystems and Biodiversity) (2010) Mainstreaming the economics of nature: a synthesis of the approach, conclusions and recommendations of TEEB. Progress Press, Malta

Tisdell C, Wilson C (2004) The public's knowledge of and support for conservation of Australia's tree-kangaroos and other animals. Biodivers Conserv 13:2339-2359

> Tisdell C, Nantha HS, Wilson C (2007) Endangerment and likeability of wildlife species: How important are they for payments proposed for conservation? Ecol Econ 60: $627-633$

> Tkac J (1998) The effects of information on willingness-topay values of endangered species. Am J Agric Econ 80: 1214-1220

> Turner RK, Adger WN, Brouwer R (1998) Ecosystem services value, research needs and policy relevance: a commentary. Ecol Econ 25:61-65

> Vatn A (2004) Environmental valuation and rationality. Land Econ 80:1-18

> Venkatachalam L (2004) The contingent valuation method: a review. Environ Impact Assess Rev 24:89-124

White P, Gregory KW, Lindley PJ, Richards G (1997) Economic values of threatened mammals in Britain: a case study of the otter Lutra lutra and the water vole Arvicola terrestris. Biol Conserv 82:345-354

- White P, Bennett AC, Hayes EJV (2001) The use of willingness-to-pay approaches in mammal conservation. Mammal Rev 31:151-167

Worm B, Barbier EB, Beaumont N, Duffy JE and others (2006) Impacts of biodiversity loss on ocean ecosystem services. Science 314:787-790

Zarzycki T (2011) Ecological and socio-economic valuation of marine biodiversity of the Gulf of Gdańsk. Institute of Oceanography, University of Gdańsk

Submitted: December 6, 2011; Accepted: July 30, 2012 Proofs received from author(s): October 8, 2012 